\title{
Urban expansion evaluation from orbital images
}

\author{
F. H. S. Ribeiro, S. C. Bettine, R. M. Longo \& A. C. Demanboro \\ Urban Infrastructure Systems, PUC-Campinas, \\ Pontifical Catholic University of Campinas, Brazil
}

\begin{abstract}
This paper aimed to validate remote sensing tools for the development of land management plans. This validation was performed from the verification of urban expansion in the city of Campinas, São Paulo, Brazil, between 1991 and 2011. For the development of the study, the geoprocessing tools were complemented with population data to generate urban population, urban expansion and population density maps for each of the macrozones of the city of Campinas. Comparing the generated maps and environmental problems present in macrozones is concluded that the sensing tools are extremely useful in designing urban master plans and, if aligned with other data, can provide the simulation of future expansion and urban density of certain area relating them to their resilience and thus lead to a city planning that meets the quality of life for all population segments. Cities must be understood in a dynamic context that is constantly changing.

Keywords: urban planning, remote sensing, orbital images, land management plans, urban expansion.
\end{abstract}

\section{Introduction}

Between 1970 and 2000 there was a substantial change in the patterns of population growth in Brazil. The high birth rates generated surplus population, industrial investments fueled migration towards the big cities and changes in the economic standard of the population led to changes in the dynamics of territorial occupation in urban centers [1]. In the case of Campinas city - second largest city in the state of São Paulo - Brazil, low-income peripheral urban occupation consolidated in the southwest region, with the incorporation of areas expanding 
towards the municipalities of Sumaré, Hortolandia, Monte-Mor and Indaiatuba; in the north-northeast axis middle and high-income occupation layers occurred, provided by the location of research and high-tech centers, as well as shopping malls and supermarkets [2].

\section{Methodology}

"Remote sensing technologies can provide a synoptic view over a large geographical area with multiple temporal intervals. Therefore, remote sensing imagery can serve as a better alternative for quantifying urban extent and monitoring urban land use changes" [3]. In this context, the Landsat 5 TM images stand out because they have good historical series and a large collection of scenes [4]. The temporal analysis, due to successive passages of satellites, allows monitoring urban expansion and detecting changes in its structure [5].

The data collection process in this work was divided into four stages: obtaining images; segmentation; classification and data consolidation. The images were derived from INPE website - National Institute for Space Research and represent Campinas in 1991 and 2011. A third image from 2004 was used as the basis for georeferencing of the previous images. For segmentation, the EX® ENVI software was used creating sets of polygons that represent parts of the image that share similar characteristics. The composition of the image on channels 4-5-3 of its spectral channels provides the visualization of urbanized areas in light blue (Figures 1(a) and 1(b)). The polygons that limit regions with these characteristics were classified as Urbanized Area and others as Not Urbanized Area (Figure 1(c)).

Table 1: Urban expansion from 1991 to 2011 in Campinas.

\begin{tabular}{|c|c|c|}
\hline Class & 1991 & 2011 \\
\hline Urbanized Area & $140 \mathrm{~km}^{2}$ & $209 \mathrm{~km}^{2}$ \\
\hline Not Urbanized Area & $651 \mathrm{~km}^{2}$ & $582 \mathrm{~km}^{2}$ \\
\hline
\end{tabular}

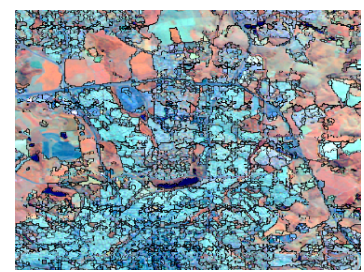

(a)

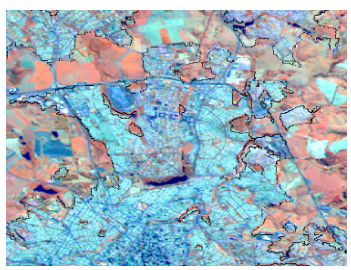

(b)

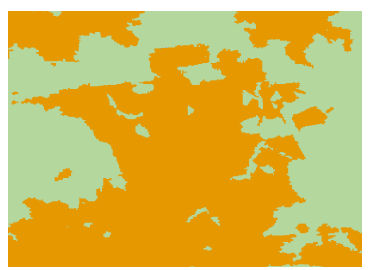

(c)

Figure 1: Classification steps: (a) set of polygons on the image to be classified; (b) polygons classified and unified according to their class; (c) classes represented by large polygons. 
For classification and consolidation of data and generation of maps, we used the Quantum GIS ${ }^{\circledR}$ and ArcGIS ${ }^{\circ}$ software, whose products are presented in the form of maps in results and discussion.

\section{Results and discussion}

The urban expansion area obtained for Campinas city between 1991 and 2011 can be seen comparing Figures 2 and 3 respectively.
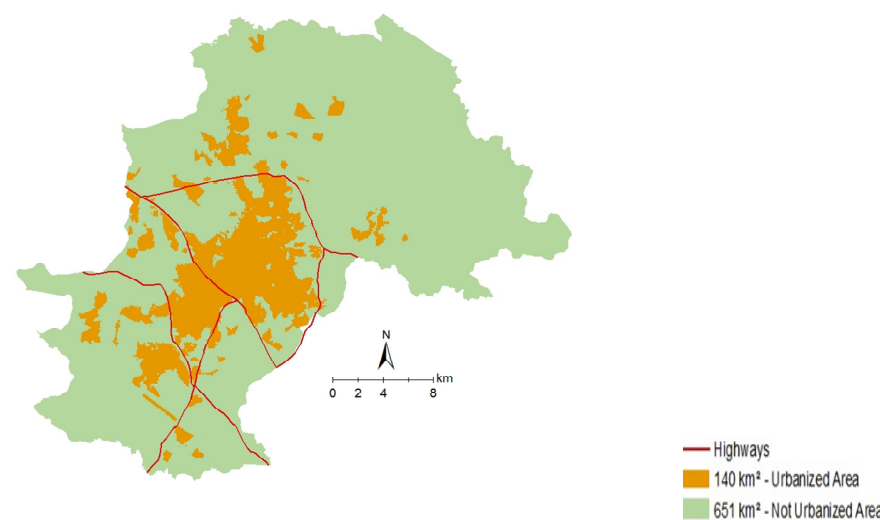

Figure 2: Campinas urbanized area in 1991.
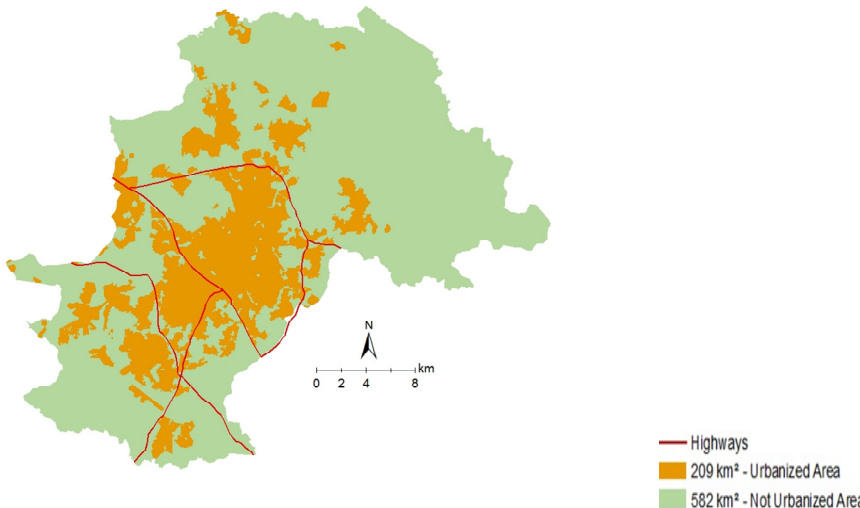

Figure 3: Campinas urbanized area in 2011.

During the period 1991-2011 the urban area expansion of Campinas city was $49 \%$, going from the urban area of $140 \mathrm{~km}^{2}$ in 1991 to $209 \mathrm{~km}^{2}$ in 2011 and for a total land area of $791 \mathrm{~km}^{2}$. A comparison of Figures 2 and 3 allowed observing that such urban expansion occurred in different directions as expected by urban expansion trends in 1991 and presented in Table 2. 
Table 2: Urban expansion trends in Campinas.

\begin{tabular}{|c|l|}
\hline Region & \multicolumn{1}{|c|}{ Trends } \\
\hline Central & $\begin{array}{l}\text { Consolidated urban area and expansion resulting from commercial, } \\
\text { service and institutional usages, as well as the intensification of } \\
\text { residential use of middle and high standard, particularly through the } \\
\text { verticalization process and the implementation of horizontal } \\
\text { condominiums. }\end{array}$ \\
\hline East & $\begin{array}{l}\text { The yet unoccupied spaces have different occupation potentials, given } \\
\text { the presence of large shopping centers. To this area significant real estate } \\
\text { investments have converged which have been changing the region } \\
\text { occupation configuration with the construction of residential gated } \\
\text { communities. }\end{array}$ \\
\hline North & $\begin{array}{l}\text { Offers potential for growth and real estate value appreciation. Urban } \\
\text { expansion in this area is induced by investments beginning in the 1970s } \\
\text { such as roads' construction and expansion, construction of University of } \\
\text { Campinas, of oil refinery and supermarkets. }\end{array}$ \\
\hline Southwest & $\begin{array}{l}\text { Rarefied periphery with low housing standard and a predominance of } \\
\text { low-income population. Type of occupation that requires significant } \\
\text { public actions in terms of infrastructure and basic equipment. Evidence } \\
\text { of pronounced conurbation without discontinuity of urban sprawl. }\end{array}$ \\
\hline South & $\begin{array}{l}\text { Recent growth vector with less pronounced conurbation trend in } \\
\text { comparison with the other regions. }\end{array}$ \\
\hline
\end{tabular}

Source: PMC, 1991 [6]. Table: authors.

Figure 4, the result from the overlapping of Figures 2 and 3, indicates the increase of the urban area that occurred in 2011 in comparison to this urban area in 1991. The portion of the image in yellow is the existing urban area in 1991, while the portion of the image in red represents the increase in urban areas from 1991 to 2011.

Table 3 shows the increase in urban population during the 1991-2010 period in each macrozone of Campinas city. The population of macrozone 6 , being predominantly rural, is not shown because its small existing urban share is accounted for in the macrozone 4.

In Table 3 it was observed that the macrozones 8, 7 and 2 showed the highest population increases during the studied period. With the data from Table 3 the maps shown in Figures 5 and 6 were generated. These figures show the urban population in 1991 and 2010 and illustrate the population quota installed in each macrozone. The population growth from 1991 to 2010 is indicated by the darker shade on the map of Figure 6-2010 - in relation to the map of Figure 5-1991. During this period the increase in the urban population of the city was $27 \%$, representing 227,130 inhabitants incorporated into the urban area, with $43.93 \%$ (99,788 inhabitants) of this population group focusing on macrozone 5 defined as a priority area of urban requalification in the Master Plan of 1991. 


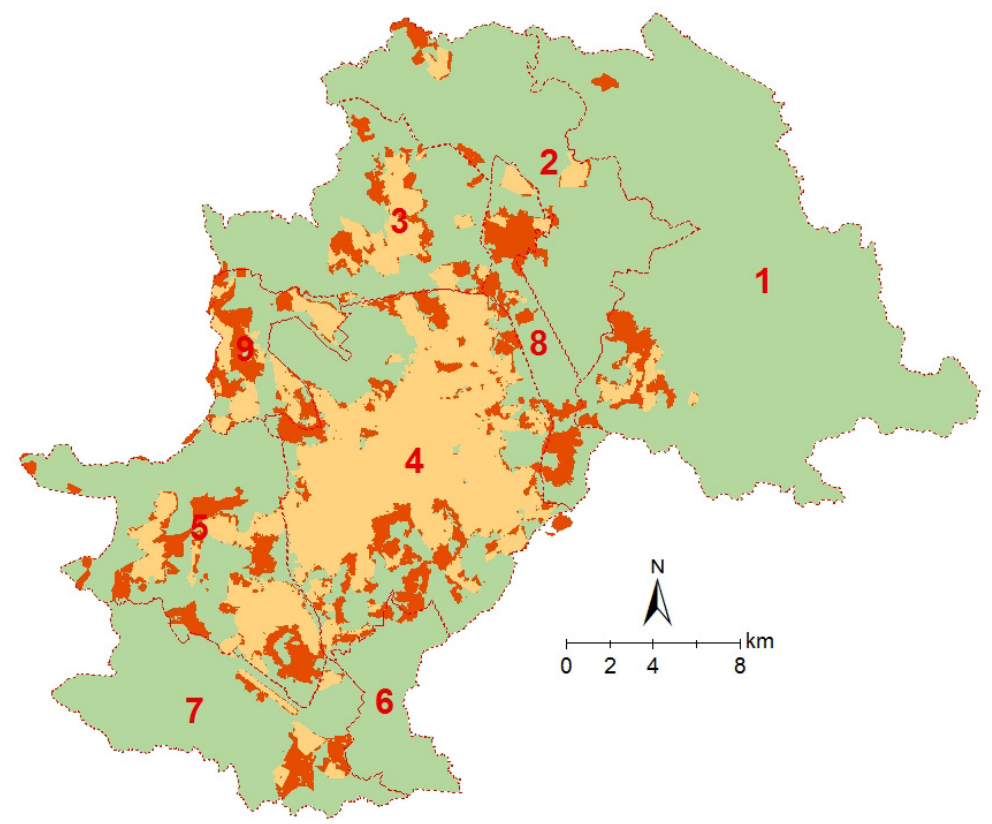

Figure 4: Overlap of urbanized areas from 1991 to 2011.

Table 3: Campinas urban population from 1991 to 2010.

\begin{tabular}{|c|c|c|c|}
\hline \multirow{2}{*}{ Macrozone } & \multicolumn{1}{|c|}{$\mathbf{1 9 9 1}$} & $\mathbf{2 0 1 0}$ & \multirow{2}{*}{ Increase } \\
\cline { 2 - 3 } & \multicolumn{2}{|c|}{ Population (inhab) } & \\
\hline 1 & 12,002 & 20,990 & $75 \%$ \\
\hline 2 & 1,925 & 5,110 & $165 \%$ \\
\hline 3 & 27,304 & 37,687 & $38 \%$ \\
\hline 4 & 590,228 & 616,915 & $5 \%$ \\
\hline 5 & 122,939 & 222,727 & $81 \%$ \\
\hline 6 & - & - & - \\
\hline 7 & 10,871 & 45,334 & $317 \%$ \\
\hline 8 & 3,815 & 16,142 & $323 \%$ \\
\hline 9 & 62,204 & 93,513 & $50 \%$ \\
\hline Total & 831,288 & $1,058,418$ & $27 \%$ \\
\hline Campinas & 847,287 & $1,080,113$ & $28 \%$ \\
\hline
\end{tabular}

Source: PMC, 1998 [7]; PMC, 2012 [8]. Table: authors. 

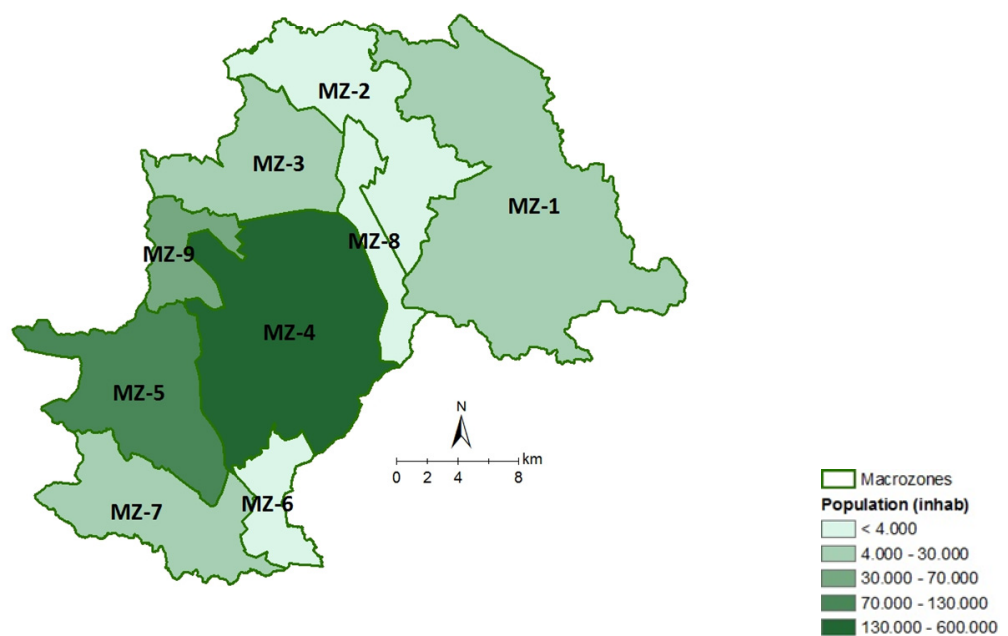

Figure 5: Macrozone urban population in 1991.
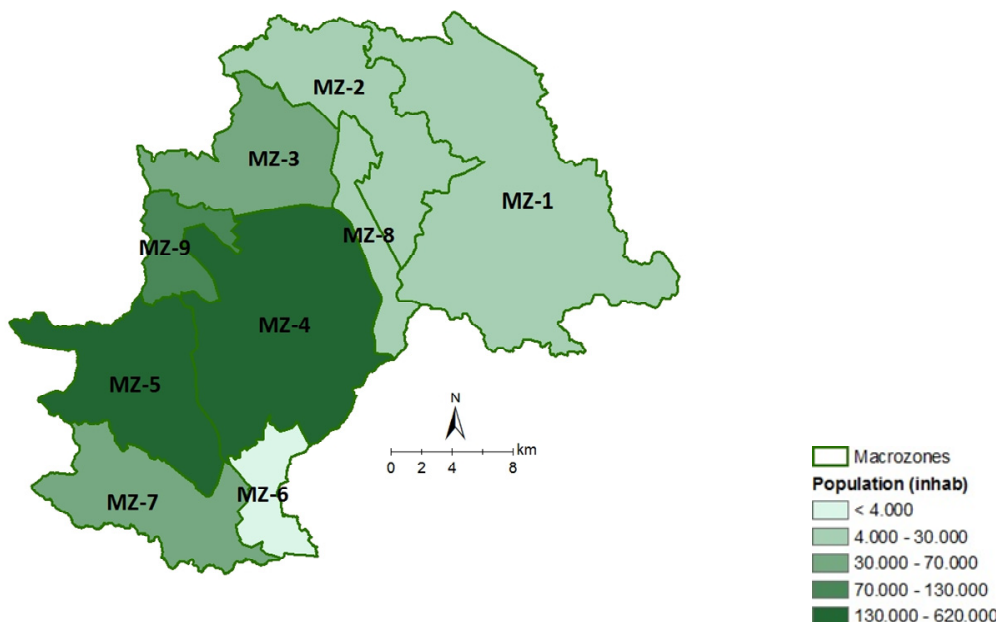

Figure 6: Macrozone urban population in 2010.

The largest relative percentage increases for the urban population occurred in macrozones 2, 7 and 8 with $165 \%, 317 \%$ and $323 \%$ respectively. The macrozone 7 is influenced by the Viracopos International Airport and macrozone 8 is relatively new and characterized by the occupation of population segments of medium and high economic levels because of the installation of a high standard real estate projects with appropriate infrastructure system.

Presented in Table 4 is the expansion of the urban area of the period from 1991 to 2011 in each one of the urban macrozones. 
Table 4: Macrozones urbanized areas from 1991 to 2011.

\begin{tabular}{|c|c|c|c|c|c|c|c|c|}
\hline \multirow{2}{*}{ Macrozone } & \multicolumn{5}{|c|}{ Area $\left(\mathbf{k m}^{2}\right)$} & \multicolumn{4}{c|}{ Area $\left(\mathbf{k m}^{2}\right)$} \\
\cline { 2 - 9 } & Urban & Not Urban & Total & \% Urban & Urban & Not Urban & Total & \% Urban \\
\cline { 2 - 9 } & \multicolumn{5}{|c|}{1991} & \multicolumn{5}{c|}{$\mathbf{2 0 1 1}$} \\
\hline 1 & 3.45 & 217.84 & 221.29 & $1.56 \%$ & 9.27 & 211.9 & 221.26 & $4.19 \%$ \\
\hline 2 & 2.43 & 87.28 & 89.71 & $2.70 \%$ & 5.71 & 83.88 & 89.59 & $6.37 \%$ \\
\hline 3 & 11.63 & 58.99 & 70.61 & $16.47 \%$ & 17.60 & 53.01 & 70.62 & $24.93 \%$ \\
\hline 4 & 89.20 & 71.23 & 160.42 & $55.60 \%$ & 106.59 & 53.64 & 160.23 & $66.52 \%$ \\
\hline 5 & 18.19 & 70.70 & 88.89 & $20.46 \%$ & 32.60 & 56.35 & 88.94 & $36.65 \%$ \\
\hline 6 & - & - & 27.80 & - & - & - & 27.80 & - \\
\hline 7 & 3.62 & 68.98 & 72.60 & $4.98 \%$ & 8.17 & 64.44 & 72.61 & $11.25 \%$ \\
\hline 8 & 2.12 & 29.17 & 31.29 & $6.78 \%$ & 12.20 & 19.09 & 31.29 & $39.00 \%$ \\
\hline 9 & 9.51 & 18.82 & 28.33 & $33.57 \%$ & 16.36 & 11.97 & 28.33 & $57.75 \%$ \\
\hline Total & 140 & 651 & 791 & $17.72 \%$ & 209 & 582 & 791 & $26.45 \%$ \\
\hline
\end{tabular}

The data of Tables 3 and 4 have produced the maps shown in Figures 7 and 8 representing the urban population density by macrozone area in 1991 and 2011 respectively. From these figures it was possible to observe the densification that occurred in macrozones 1, 2, 3, 5, 7, 8 and 9. However, Figures 7 and 8 have a dividend (urban population) and a divider (macrozone territory), then, they do not show, right away, that crowded areas are directly close-peopled areas as well. The most appropriate divider to this trend is the urban area of Figures 9 and 10.
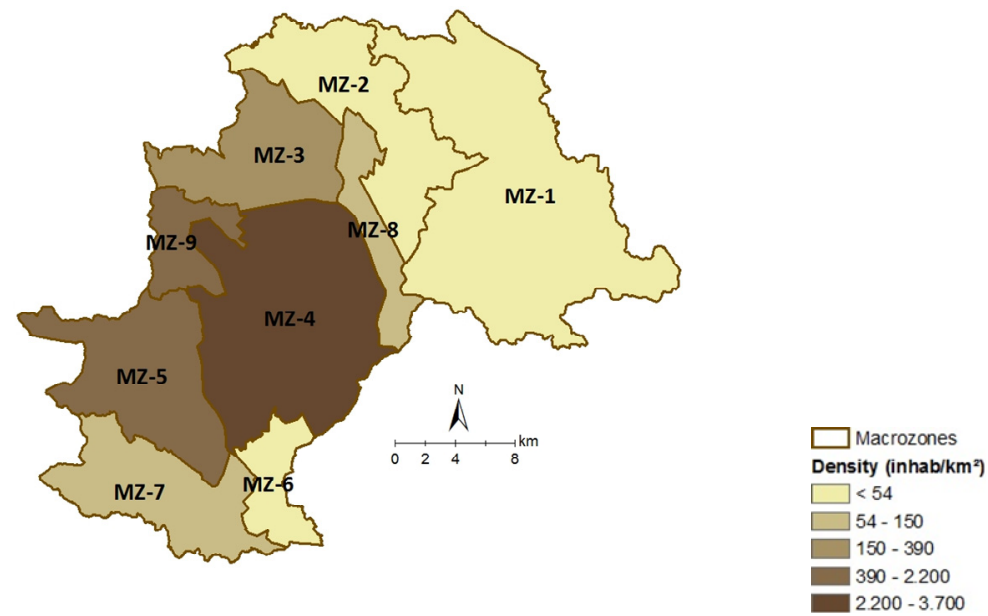

Figure 7: Urban population density by macrozone area in 1991. 

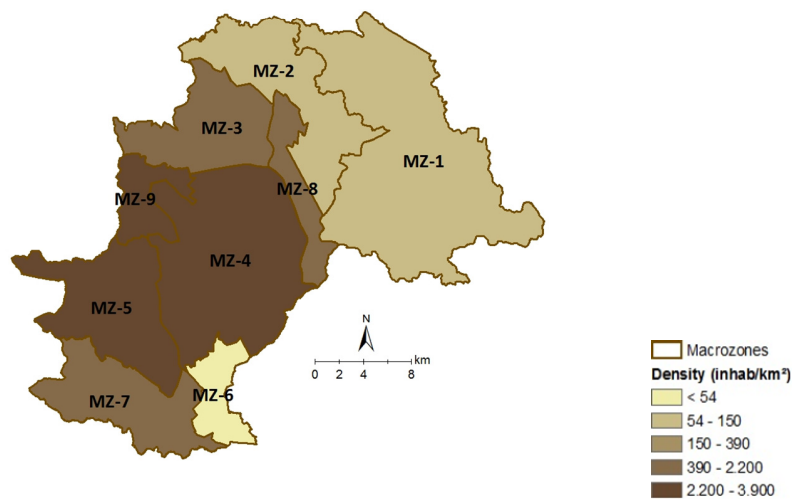

Figure 8: $\quad$ Urban population density by macrozone area in 2011.
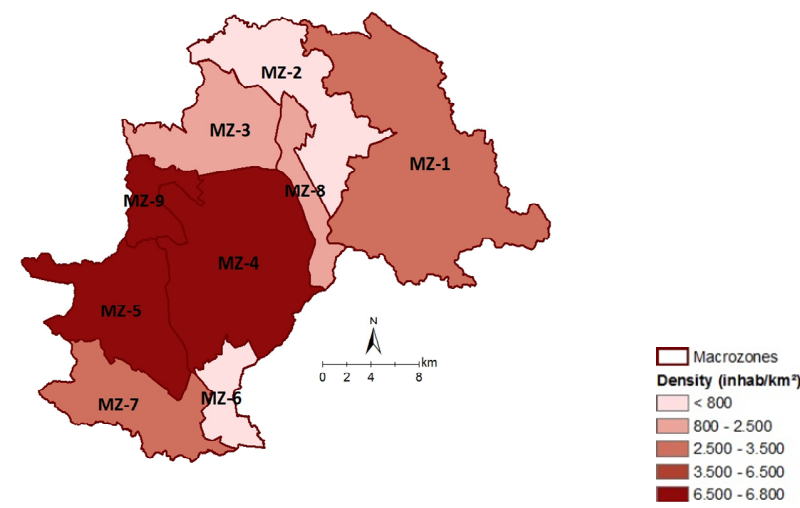

Figure 9: Urban population density by macrozone urbanized area in 1991.
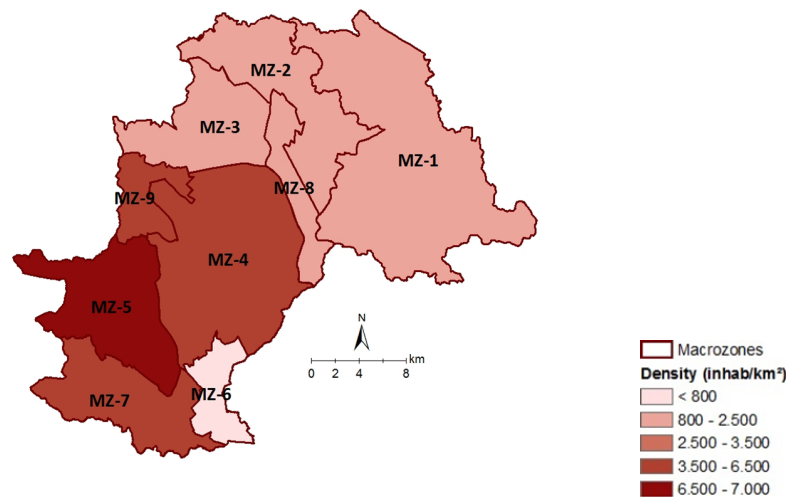

Figure 10: Urban population density by macrozone urbanized area in 2011. 
The urban spacing reflects the occupation of new areas and/or the expansion of other ones, moved largely by the increase in population. Certain areas, already consolidated, do not allow the visualization of population increase from the spacing, but from the population densification that can only be confirmed with the crossing of the census data.

The analysis of Figures 7 and 8 may show the populational trend, while the analysis of Figures 9 and 10 intends to demonstrate the settlement trend. The reflection of the percentage relationship between population growth and urban area is clearly observed in the comparison of these maps. The increased population density provided by a percentage lower urban expansion that the population of macrozones 2 and 7 is indicated by darkening of tone of your classes - the macrozone 5 remained in the darkest class despite the increase. Likewise, decreasing the density is indicated by lighter shades in Macrozones 1 , 4 and 9 in relation to the other macrozones.

The urban occupation in Campinas city from 1991 to 2011 - Figures 2 to 10 was characterized by saturation of the central regions, by the consolidation of urban voids resulting from real estate speculation coming from large conglomerates owners of these areas and by the expansion of peripheral areas with low land value because of the lack of infrastructure services.

\section{Conclusion}

It is understood that the obtaining of territorial data using geoprocessing tools is of great importance in the territorial planning process. This tool can provide information of past and present times, enabling the creation of a database that helps in land management projects because it allows the visualization of expected trends in previous plans, pinpoints new trends of urban expansion and allows also the maintenance and adequacy of management plans, especially in regards to environmental matters, allowing to see over time what actions are being implemented in each area and in which cases they are contrary to the guidelines previously planned.

Another point to note is the possibility of crossing the territorial data, obtained by the classification process, with census data; this data fusion creates a variety of information that, by allowing to generate different themed maps, applies itself at different levels and areas of urban planning.

It's then possible to observe, throughout the development of this work, the opportunity for integration of remote sensing tools with other different data, which allows a better understanding of the problems resulting from the urban occupation and expansion. This plurality makes these tools needful for urban planning and management.

\section{Acknowledgement}

The Pontifical Catholic University of Campinas - PUC-Campinas. 


\section{References}

[1] Braga, F.G. Migração Interna e Urbanização no Brasil Contemporâneo: Um estudo da Rede de Localidades Centrais do Brasil (1980/2000). Encontro Nacional de Estudos Populacionais, 15, 2006, Caxambú-MG.

[2] Cano, W. e Brandão, C.A. A região metropolitana de Campinas: urbanização, economia, finanças e meio ambiente. Campinas: Editora da Unicamp, 2002.

[3] Lu et al., 2004 apud Zang, S.Y.; Wu, C.S.; Liu, H.; Na, X.D. Impact of urbanization on natural ecosystem service values: a comparative study. Environmental Monitoring and Assessment, 2011.

[4] Barros, L.C.; Dutra, L.V.; Macedo, D.R. Utilização de imagens espectrais de média resolução espacial na análise da expansão urbana do município de Betim (RMBH) por meio de modelo de mistura. Simpósio Brasileiro de Sensoriamento Remoto, 13, 2007, Florianópolis-SC.

[5] Pisani, M.A.J.; Zmitrowicz, W. Sensoriamento remoto via orbital aplicado a estudos urbano. Boletim Técnico da Escola Politécnica da USP, São Paulo, 1992.

[6] PMC (Campinas City Hall), Department of Public Works and Services. Subsídios para discussão do Plano Diretor. Campinas, 1991.

[7] PMC (Campinas City Hall), Department of Urban Planning and Development. Sumário de dados: População, Campinas e Região. Campinas, 1998.

[8] PMC (Campinas City Hall), Department of Urban Planning and Development, Planning Department, Coordination Sector of Socioeconomic Planning. Campinas, 2012. Available in https://docs.google.com/ spreadsheet/pub?key=0Amj0mSYLXRsfdE9RcGRfdmpOLVNZZW5yN1Z $\mathrm{kRkVXeWc \& output}=\mathrm{html}$ 